\title{
Tailored Magnetic Multicore Nanoparticles for Use as Blood Pool MPI Tracers
}

\author{
Harald Kratz ${ }^{1, *} \mathbb{1}$, Azadeh Mohtashamdolatshahi ${ }^{1}{ }^{\oplus}$, Dietmar Eberbeck ${ }^{2}$, Olaf Kosch ${ }^{2}$, Frank Wiekhorst ${ }^{2}{ }^{(0)}$, \\ Matthias Taupitz ${ }^{1} \mathbb{D}$, Bernd Hamm ${ }^{1}$, Nicola Stolzenburg ${ }^{1}$ and Jörg Schnorr ${ }^{1}$
}

1 Department of Radiology, Charité-Universitätsmedizin Berlin, Corporate Member of Freie Universität Berlin and Humboldt-Universität zu Berlin, D-10117 Berlin, Germany; Azadeh.Mohtashamdolatshahi@charite.de (A.M.); Matthias.Taupitz@charite.de (M.T.); Bernd.Hamm@charite.de (B.H.); Nicola.Stolzenburg@charite.de (N.S.); Joerg.Schnorr@charite.de (J.S.)

2 Physikalisch-Technische Bundesanstalt, D-10587 Berlin, Germany; Dietmar.Eberbeck@ptb.de (D.E.); Olaf.Kosch@ptb.de (O.K.); Frank.Wiekhorst@ptb.de (F.W.)

* Correspondence: Harald.Kratz@charite.de; Tel.: +49-30-450-527180

check for updates

Citation: Kratz, H.;

Mohtashamdolatshahi, A.; Eberbeck

D.; Kosch, O.; Wiekhorst, F.; Taupitz,

M.; Hamm, B.; Stolzenburg, N.;

Schnorr, J. Tailored Magnetic Multicore

Nanoparticles for Use as Blood Pool MPI Tracers. Nanomaterials 2021, 11, 1532. https://doi.org/10.3390/ nano11061532

Academic Editor: Lyudmila M. Bronstein

Received: 19 April 2021

Accepted: 7 June 2021

Published: 10 June 2021

Publisher's Note: MDPI stays neutral with regard to jurisdictional claims in published maps and institutional affiliations.

Copyright: (c) 2021 by the authors. Licensee MDPI, Basel, Switzerland. This article is an open access article distributed under the terms and conditions of the Creative Commons Attribution (CC BY) license (https:/ / creativecommons.org/licenses/by/ $4.0 /)$.

\begin{abstract}
For the preclinical development of magnetic particle imaging (MPI) in general, and the exploration of possible new clinical applications of MPI in particular, tailored MPI tracers with surface properties optimized for the intended use are needed. Here we present the synthesis of magnetic multicore particles (MCPs) modified with polyethylene glycol (PEG) for use as blood pool MPI tracers. To achieve the stealth effect the carboxylic groups of the parent MCP were activated and coupled with pegylated amines (mPEG-amines) with different PEG-chain lengths from 2 to $20 \mathrm{kDa}$. The resulting MCP-PEG variants with PEG-chain lengths of $10 \mathrm{kDa}$ (MCP-PEG10K after one pegylation step and MCP-PEG10K2 after a second pegylation step) formed stable dispersions and showed strong evidence of a successful reaction of MCP and MCP-PEG10K with mPEG-amine with $10 \mathrm{kDa}$, while maintaining their magnetic properties. In rats, the mean blood half-lives, surprisingly, were 2 and $62 \mathrm{~min}$, respectively, and therefore, for MCP-PEG10K2, dramatically extended compared to the parent $\mathrm{MCP}$, presumably due to the higher PEG density on the particle surface, which may lead to a lower phagocytosis rate. Because of their significantly extended blood half-life, MCP-PEG10K2 are very promising as blood pool tracers for future in vivo cardiovascular MPI.
\end{abstract}

Keywords: magnetic particle imaging (MPI); magnetic particle spectroscopy (MPS); magnetic nanoparticles (MNP); magnetic multicore particles (MCP); coprecipitation; polyethylene glycol (PEG); blood half-life

\section{Introduction}

Magnetic nanoparticle (MNP) based on iron oxides have been the subject of medical research and development for decades. They have many applications including magnetically induced hyperthermia for cancer treatment [1,2], iron replacement therapy [3], bioassays $[4,5]$ and as contrast agents for medical and molecular imaging by magnetic resonance imaging (MRI) [6,7] or magnetic particle imaging (MPI) [8]. MNP used as contrast agents typically consist of an iron oxide core with an appropriate coating for stabilization. The iron oxide core itself predominantly consists of magnetite, maghemite or a magnetite/maghemite mixed phase. In addition, their magnetic characteristics for use as contrast agents for MRI or as MPI tracers must meet specific criteria. MPI was introduced by Weizenecker and Gleich in 2005 as a new radiationless imaging modality which provides $4 \mathrm{D}$ imaging with high temporal resolution ( 46 frames per second) and a spatial resolution on the order of $1 \mathrm{~mm}$, depending on the type of MPI scanner and MPI tracer used [9]. Since only the dynamic magnetic response of the MNP exposed to an oscillating excitation field is inductively detected, the surrounding tissue does not contribute any signal to the MPI image. Therefore, certain medical applications crucially rely on the combination of 
MPI with other imaging modalities like MRI to obtain related anatomical information [10]. MPI can quantitatively determine tracer distribution and distinguish between different binding states of the MNP, for example, if the particles are unbound in dispersion, bound to a surface or are taken up by cells [11-13]. Promising imaging applications for preclinical imaging are stem cell tracking $[14,15]$ and immune cell tracking $[16,17]$ as well as imaging of the cardiovascular system [17-20] and local perfusion [21,22]. To address these applications and to find possible new clinical applications, it is pivotal to develop tailored MPI tracers with specific properties. Magnetic multicore particles (MCPs) were developed for MPI by a modified cost-effective coprecipitation method. Monodispersity, which is crucial for a good MPI performance, is achieved by fractional magnetic separation and the very good magnetic properties, by an annealing process $[9,23,24]$. In MCPs, small single crystallite cores are combined to form larger nanoparticles, which have already shown very good MPI tracer performance along with excellent in vivo behavior in rats [25-28]. MCPs are coated with carboxymethyl dextran (CMD) and therefore negatively charged at physiological $\mathrm{pH}$. The negative $\zeta$-potential of about $-33.5 \mathrm{mV}$ leads to an increased cellular uptake of these particles compared to MNP with an uncharged surface $[25,29]$. The high cellular uptake enables the use of MCPs for potential single cell tracking using MPI or MRI [30]. On the other hand, due to enhanced uptake in the liver and spleen, the in vivo blood half-life after intravenous (i.v.) injection is limited, and therefore, their use as MPI tracers for imaging of the cardiovascular system is also limited [17-19]. The negative charge of MCPs is attributable to carboxyl groups located on their surface, which can be used for coupling reactions and therefore for modulating MNP surface characteristics [25]. A very common method to achieve an extended in vivo blood half-life is to coat the MNP surface with polyethylene glycol (PEG) [31]. This technique is well established for the modification of nanoparticles and also proteins, among other things [32-35]. PEG has a very high water-binding capacity and hence strongly reduces interaction of the particle surface with proteins, which in turn leads to a reduced recognition of the respective pegylated MNP by the immune system [31]. Our hypothesis was therefore that it should be possible to anchor PEG derivatives on the surface of MCPs to achieve a prolonged in vivo blood half-life. In the following we describe the development of these pegylated MCPs, their physicochemical characterization and first in vivo blood half-life studies using MRI.

\section{Materials and Methods}

\subsection{Chemicals}

Unless otherwise noted, all Chemicals were purchased from Sigma-Aldrich (Steinheim, Germany) and were used without any further purification. Methoxy polyethylene glycol amine (mPEG-amine) with molecular weights of $2 \mathrm{kD}, 5 \mathrm{kD}, 10 \mathrm{kD}$ and $20 \mathrm{kD}$ (mPEG-amine $2 \mathrm{~K}-20 \mathrm{~K}$ ) were purchased from Laysan Bio. Inc. (Arab, AL, USA). Deionized water was produced using a Milli-Q A10 system (Millipore, Billerica, MA, USA) and was used to prepare all solutions and dispersions.

\subsection{MPI Tracers}

Here, the syntheses of 3 variants of pegylated MCPs using $5 \mathrm{kD}$ and $10 \mathrm{kD}$ mPEGamine, leading to MCP-PEG5K, MCP-PEG10K and MCP-PEG10K2 are described. The syntheses of pegylated MCPs using $2 \mathrm{kD}$ and $20 \mathrm{kD}$ mPEG-amine, leading to MCP-PEG2K and MCP-PEG20K, are described in supplement Protocols S1 and S2.

\subsubsection{MCPs}

MCPs were synthesized in our laboratory according to a previously published synthesis protocol and are coated with carboxymethyl dextran (CMD) [25,26]. After synthesis, the MCPs were concentrated to approx. $300 \mathrm{mmol} \mathrm{Fe} / \mathrm{L}$ by centrifugation with $3112 \times g$ using Amicon Ultra-15 Centrifugal Filter Units (PLHK Ultracel-PL Membrane, 100 kDa). MNP dispersions were diluted with Milli-Q water to prepare the respective final concentrations and stored in a fridge at $4{ }^{\circ} \mathrm{C}$. 


\subsubsection{Synthesis of MCP-PEG5K and MCP-PEG10K}

An amount of $1.80 \mathrm{~mL} \mathrm{MCP}$ dispersion $(108.4 \mathrm{mM} \mathrm{Fe} / \mathrm{L})$ was subsequently mixed with a solution of $0.180 \mathrm{~g}(829 \mu \mathrm{mol}) \mathrm{N}$-hydroxysulfosuccinimide sodium salt (sulfoNHS) in $0.45 \mathrm{~mL}$ water and a solution of $0.54 \mathrm{~g}(2.817 \mathrm{mmol}) \mathrm{N}$-(3-dimethylaminopropyl)$N^{\prime}$-ethylcarbodiimide hydrochloride (EDC) in $1.35 \mathrm{~mL}$ water. Thereafter, the mixture was agitated for $30 \mathrm{~min}$ at room temperature (RT) in a Roto-Therm Plus rotary blender (Benchmark, Sayreville, NJ, USA). The particle dispersion was then centrifuged at $780 \times g$ for $4 \mathrm{~s}$, and $3.6 \mathrm{~mL}$ of the supernatant was removed and replaced by $3.6 \mathrm{~mL}$ of water and the mixture was vortexed. The particle dispersion was then centrifuged a second time at $780 \times \mathrm{g}$ for $4 \mathrm{~s}$ and $3.6 \mathrm{~mL}$ of the supernatant was removed, $3.6 \mathrm{~mL}$ of water was added, and the mixture was vortexed again. Following these steps, the dispersion was added to a solution of $0.9 \mathrm{~g}(180 \mu \mathrm{mol}) \mathrm{mPEG}-\mathrm{amine} 5 \mathrm{~K}(5 \mathrm{kD})$ in $3.6 \mathrm{~mL}$ of water for MCP-PEG5K or $1.8 \mathrm{~g}(180 \mu \mathrm{mol}) \mathrm{mPEG}-a m i n e 10 \mathrm{~K}(10 \mathrm{kD})$ in $3.6 \mathrm{~mL}$ of water for MCP-PEG10K. After thorough mixing, the resulting batch was sonicated for 99 min using a Sonorex Digiplus DL $512 \mathrm{H}$ Sonicator (Bandelin, Berlin, Germany) at 100\% intensity (the temperature rose from RT to $48^{\circ} \mathrm{C}$ ) and then mixed at RT with a Roto-Therm Plus rotary blender at RT overnight. Water was then added to reach a total volume of about $30 \mathrm{~mL}$, and the dispersion was concentrated to a volume of about $1 \mathrm{~mL}(2 \times 500 \mu \mathrm{L})$ using two centrifuge filters $(100 \mathrm{kD}$ Ultracel Amicon Ulta 15,) at $3939 \times \mathrm{g}$. Then $3 \mathrm{~mL}$ of water were added in each case, and the dispersion was again concentrated to about $500 \mu \mathrm{L}$ of volume at $3939 \times g$. The last step, addition of water and subsequent centrifugation, was repeated three more times, and the volume of the resulting dispersion was collected and increased to a total volume of $1.1 \mathrm{~mL}$ by adding water. Iron content for MCP-PEG5K: $149 \mathrm{mM} \mathrm{Fe} / \mathrm{L}$ (yield: $84 \%$ related to Fe); Iron content for MCP-PEG10K: $146 \mathrm{mM} \mathrm{Fe} / \mathrm{L}$ (yield: 82\% related to Fe).

\subsubsection{Synthesis of MCP-PEG10K2 by Renewed Conversion of MCP-PEG10K with mPEG-amine10K}

An amount of $0.60 \mathrm{~mL}$ MCP-PEG10K dispersion (116.6 mM Fe/L) was subsequently mixed with a solution of $0.060 \mathrm{~g}(276 \mu \mathrm{mol})$ sulfo-NHS in $0.15 \mathrm{~mL}$ water and a solution of $0.18 \mathrm{~g}(0.939 \mathrm{mmol}) \mathrm{EDC}$ in $0.45 \mathrm{~mL}$ water. Thereafter, the mixture was agitated for $30 \mathrm{~min}$ at $\mathrm{RT}$ in a rotary blender. The particle dispersion was then concentrated using two centrifuge filters $(100 \mathrm{kD}, \mathrm{RC}$, Ultracel, Amicon Ultra 0.5) at $9900 \times g$ to a volume of $180 \mu \mathrm{L}$ $(2 \times 90 \mu \mathrm{L})$. The resulting dispersion was diluted with water to a total volume of $1 \mathrm{~mL}$ and then added to a solution of $0.6 \mathrm{~g}(60 \mu \mathrm{mol}) \mathrm{mPEG}$-amine $10 \mathrm{~K}(10 \mathrm{kD})$ in $1.2 \mathrm{~mL}$ of water. After thorough mixing, the resulting batch was sonicated for 99 min using a Sonorex Digital 10 P Sonicator (Bandelin, Berlin, Germany) at $100 \%$ of intensity (the temperature rose from RT to $50{ }^{\circ} \mathrm{C}$ ) and then mixed at RT with a Roto-Therm Plus rotary blender (Benchmark, Sayreville, NJ, USA) at RT overnight. Water was then added to reach a total volume of about $20 \mathrm{~mL}$, and the dispersion was concentrated to a volume of about $0.8 \mathrm{~mL}(2 \times 400 \mu \mathrm{L})$ using two centrifuge filters (100 kD, Ultracel Amicon Ulta 4 ,) at $3372 \times g$. Then $3 \mathrm{~mL}$ of water were added in each case, and the dispersion was again concentrated to about $300 \mu \mathrm{L}$ of volume at $3372 \times g$. The last step, addition of water and subsequent centrifugation, was repeated three more times, and the volume of the resulting dispersion was collected and increased to a total volume of $0.4 \mathrm{~mL}$ by adding water. Iron content for MCP-PEG10K2: $163 \mathrm{mM} \mathrm{Fe} / \mathrm{L}$ (yield: 93\% related to Fe).

\subsection{Nanoparticle Characterization}

The iron content of the particle dispersions was colorimetrically determined using the phenanthroline method [36]. The hydrodynamic diameter distribution, weighted by volume $\left(\mathrm{d}_{\mathrm{V}}\right)$, the intensity-weighted mean hydrodynamic size (Z-Average), the polydispersity index (PDI), and the $\zeta$-potential of the MNP were determined by dynamic light scattering (DLS) on a Zetasizer Nano ZS particle analyzer (Malvern Instruments, Worcestershire, UK). For DLS, PDI and Z-Average measurement, MNP dispersions were diluted with Milli-Q water to a final concentration of $1 \mathrm{mmol} \mathrm{Fe} / \mathrm{L}$. For $\zeta$-potential measurement, MNP disper- 
sions were diluted with $10 \mathrm{mM} \mathrm{NaCl}$ to a final concentration of $1 \mathrm{mmol} \mathrm{Fe} / \mathrm{L}$ and adjusted to a $\mathrm{pH}$ of about 7.20 with $\mathrm{NaOH}$. Short- and long-term stability of the MNP dispersions were investigated by visual inspection and by DLS. Nanoparticle size, morphology and phase were analyzed by transmission electron microscopy (TEM) using a TECNAI G2 20 S-Twin and a TITAN 80-300 (FEI Company, Hillsboro, OR, USA). ${ }^{1}$ H-NMR T1- and T2-relaxation rates were measured with a Minispec MQ 40 Time-Domain Nuclear magnetic resonance (TD-NMR) spectrometer at $40{ }^{\circ} \mathrm{C}$ and $0.94 \mathrm{~T}$ (Bruker, Karlsruhe, Germany). Relaxivities (relaxation coefficients) r1 and r2 were determined by linear fitting of T1and T2-relaxation rates as functions of iron concentrations. MNP were also analyzed by magnetic particle spectroscopy (MPS) to obtain information on their response to alternating magnetic fields. MPS measurements were performed on undiluted samples using a magnetic particle spectrometer (MPS-3, Bruker BioSpin, Germany) at $12 \mathrm{mT}, 25 \mathrm{kHz}$ and $37^{\circ} \mathrm{C}$ for $10 \mathrm{~s}$. For measurement the samples were filled in Life Technologies polymerase chain reaction (PCR) tubes with sample volumes of $30 \mu \mathrm{L}$. The amplitude of the magnetic moment was normalized to the iron content of each sample, resulting in the spectrum of the magnetization, $M_{k}$, which is given in $\mathrm{Am}^{2} / \mathrm{mol}(\mathrm{Fe})$.

To obtain an adequate reference for the immobilized state of MCP-PEG10K2 in organs, MNP were immobilized in polyacrylamide gel (PAA). For this, $94 \mu \mathrm{L}$ acrylamide solution

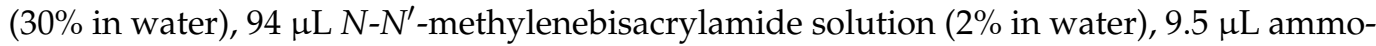
nium persulfate (1\% in water), $24 \mu \mathrm{L}$ water, $60 \mu \mathrm{L}$ MCP-PEG10K2 dispersion (10.6 mmol $(\mathrm{Fe}) / \mathrm{L})$, and $18.5 \mu \mathrm{L} N, N, N^{\prime}, N^{\prime}$-tetramethyletylenediamine (1:30 diluted with water $\left.(v / v)\right)$ were mixed and subsequently vortexed. Finally, $50 \mu \mathrm{L}$ of the resulting dispersion was filled in a measuring cuvette and polymerized at $60^{\circ} \mathrm{C}$ in a water bath for approx. $3 \mathrm{~min}$. For $\mathrm{M}(\mathrm{H})$ measurement, $75 \mu \mathrm{L}$ sample volumes were filled in a polycarbonate capsule. The magnetic moment of each sample was measured using an MPMS (Magnetic Property Measurement System, Quantum Design, San Diego, CA, USA) consecutively increasing the applied magnetic field from 0 to $5 \mathrm{~T}$. The background signal caused by empty capsules, diamagnetic susceptibility of the dispersion medium, and demineralized water, was subtracted from the signal obtained for the samples. The resulting data represent MNP magnetization and were normalized to the iron content of the sample, which allows quantitative evaluation of the data. Since the $\mathrm{M}(\mathrm{H})$ did not saturate even at highest measurement fields, the value of $M$, at $H=448 \mathrm{kA} / \mathrm{m}$ was taken as a substitute of the saturation magnetization $\left(M_{S}\right)$. This field value was found to be a good compromise between a small change of $M$ with $H$ and a low uncertainty. Note that the uncertainty increases with the field value because of potential errors during background subtraction. Because of possible small deviation of the sample from the center position in the MPMS, we give an uncertainty of the absolute values of 5\%. FTIR measurements were performed using a Bruker ALPHA spectrometer (model A250/D, Bruker Optik GmbH, Leipzig, Germany) equipped with a diamond ATR sampling module (model A220/D-01, Bruker Optik GmbH, Leipzig, Germany). Measured data were processed using the OPUS 6.5 software package (Bruker Optik $\mathrm{GmbH}$, Leipzig, Germany). Background and baseline correction as well as atmospheric compensation were applied to all spectra. Spectra were acquired in absorbance mode and converted to transmission mode from 23 coadded scans between 4000 and $375 \mathrm{~cm}^{-1}$.

\subsection{In Vivo MRI Studies}

\subsubsection{In Vivo MR Imaging for Determination of MNP Blood Half-Life and Organ Distribution}

Rats were kept in Type IV Macrolon1 cages (Zoonlab, Castrop-Rauxel, Germany) on softwood granulate (Lignocel, J. Rettenmaier, Rosenberg, Germany) at a constant 12-h day/night cycle, a temperature of $21 \pm 1^{\circ} \mathrm{C}$, and $50 \pm 5 \%$ relative humidity according to recommendation 2007/526/EC of the European Commission. Rats received commercial standard pellet feed (ssniff, R-M-H, Soest, Germany) and tap water ad libitum. In vivo experiments in rats were conducted in accordance with the requirements and guidelines of EU directive 2010/63/EU and the German Animal Protection Act. The animal studies were approved by the State Office of Health and Social Affairs Berlin (LAGESO) and were 
carried out in accordance with institutional and federal animal care guidelines. Images were acquired on a clinical 1.5 Tesla (Magnetom Sonata; Siemens Healthcare Solutions, Erlangen, Germany) and a 3 Tesla MRI scanner (Magnetom Lumina, Siemens Healthcare Solutions, Erlangen, Germany) using the 18-channel extremity coil (note: the initially used MRI scanner was replaced during the conduct of the study). In vivo examinations were carried out on 5 healthy male Sprague Dawley rats (Charles River Laboratories, Sulzfeld, Germany), 12 weeks old, with an average body weight of $355 \pm 15 \mathrm{~g}$. Prior to MRI, rats were anesthetized with $5 \%$ isoflurane in an anesthetic induction chamber and maintained in 1-2\% isoflurane during MRI acquisitions. The MNP dispersions were injected into a lateral tail vein at a final dose of $50 \mu \mathrm{mol} \mathrm{Fe} / \mathrm{kg}$ of bodyweight as a bolus over 2 s. Imaging was performed in coronal orientation with a T1-weighted 3D fast low-angle shot (FLASH) sequence every 5 to $10 \mathrm{~min}$ after MNP administration over a 90-min period. Further imaging parameters were: repetition time (TR) $=6.57 \mathrm{~ms}($ at $3 \mathrm{~T})$ and $\mathrm{TR}=5.7 \mathrm{~ms}($ at $1.5 \mathrm{~T})$, echo time $(\mathrm{TE})=1.95 \mathrm{~ms}$, flip angle $(\mathrm{FA})=25^{\circ}$, field of view $(\mathrm{FOV})=300 \times 300 \mathrm{~mm}$, matrix size $=784 \times 896($ reconstructed pixel size $=0.3 \times 0.3 \mathrm{~mm})$ and slice thickness $=0.6 \mathrm{~mm}, 80$ slices, bandwidth of $130 \mathrm{~Hz} / \mathrm{Px}$ (at 3T) and $200 \mathrm{~Hz} / \mathrm{Px}$ (at $1.5 \mathrm{~T}$ ). Qualitative biodistribution of MNP in liver and spleen was assessed using T2 * weighted images acquired in transverse orientation with a spoiled gradient echo (GRE) sequence before and after MNP administration ( $24 \mathrm{~h}$ post). Further imaging parameters were: $\mathrm{TR} / \mathrm{TE}=309,4.02 \mathrm{~ms}, \mathrm{FA}=25^{\circ}, \mathrm{FOV}=200 \times 200 \mathrm{~mm}$, matrix size $=288 \times 288$ (pixel size $=0.7 \times 0.7 \mathrm{~mm}$ ) and slice thickness $=1.5 \mathrm{~mm}, 18$ slices, bandwidth of $404 \mathrm{~Hz} / \mathrm{Px}$ (at 3T). MNP blood half-life was assessed in three regions of interest (ROIs) defined over the inferior vena cava of each animal at each time point up to $90 \mathrm{~min}$ after injection. From the average value in the ROIs at each time point, half-life was calculated as first-order exponential decay kinetics using GraphPad Prism software version 7 (GraphPad Software, San Diego, CA, USA).

\subsubsection{Quantification of MNP Biodistribution by MPS}

Ex vivo MPS measurements of removed organs were performed in a commercial magnetic particle spectrometer (Bruker, Germany) with sinusoidal magnetic signal excitation using an amplitude of $25 \mathrm{mT}$, a frequency of $25 \mathrm{kHz}$ and a sample temperature of $37^{\circ} \mathrm{C}$. The nonlinear magnetization response of MNPs in organs was measured for $10 \mathrm{~s}$ by a pickup coil (sensitivity: 10-12 $\mathrm{Am}^{2}$ ). All MPS sample measurements were corrected by subtraction of the background signal of the empty sample holder from the MPS spectra. For MPS measurement the removed organs were cut into small pieces using a ceramic scalpel to avoid iron contamination. A PAA-embedded sample of MCP-PEG10K2 was used as a reference for iron quantification, which showed a close match of spectra (by the MPS shape parameter A5/A3) with the tissue samples. For quantification, the amplitude of the 3rd harmonic of the MPS spectra of measured samples was normalized to the amplitude of the reference sample (for MPS spectrum of this reference, please see supplement Figure S6).

\section{Results and Discussion}

\subsection{Nanoparticle Synthesis and Characterization}

In this work, we synthesized pegylated MCPs (MCP-PEG) by activation of the carboxyl groups of MCPs using an EDC/sulfo-NHS strategy and subsequent conversion of the intermediately formed sulfo-NHS active ester with mPEG-amines of different chain lengths (Figure 1). 


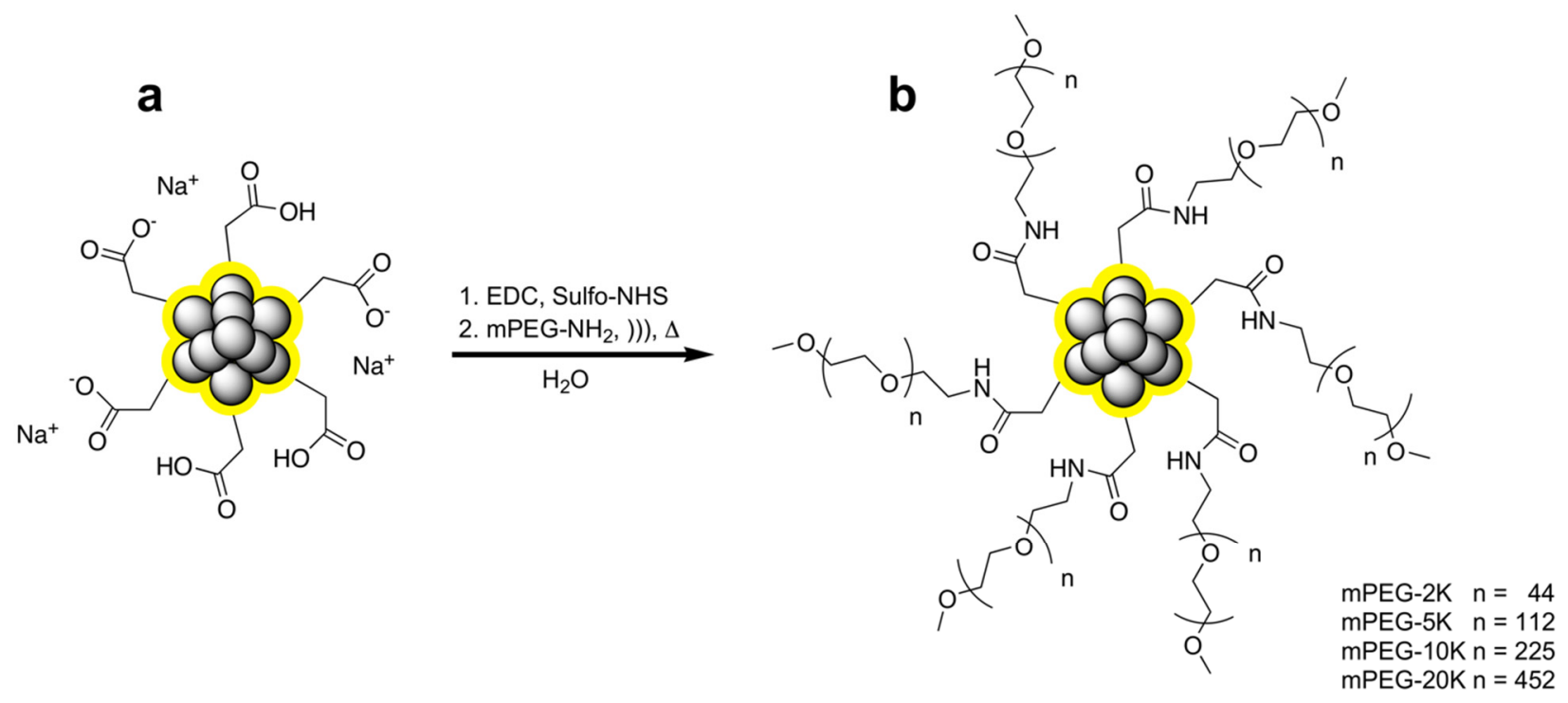

\section{MCP}

MCP-PEG

Figure 1. Activation of MCPs (a) with EDC and sulfo-NHS and subsequent conversion with mPEG-amines of different chain lengths to obtain the corresponding MCP-PEG variants (b).

Synthesis was performed with different mPEG-amine derivatives with molecular weights of 2, 5, 10 and $20 \mathrm{kD}$ molecular weight. Depending on the molecular weight of the converted mPEG-amines and to prevent aggregation of the MNP during conversion the reactions were performed in an ultrasonic bath and, in some cases, at higher temperatures. Because of the sensitivity of PEG and CMD to high intensity ultrasound, a low-energy ultrasonic cleaning bath was used to prevent degradation of the coating polymers [37-39]. Dispersion stabilities of the MCP-PEG variants obtained by conversion are shown in Table 1.

Table 1. MCP-PEG variants obtained by conversion of MCPs with different mPEG-amines.

\begin{tabular}{cc}
\hline MCP-PEG Variant & Dispersion Stability \\
\hline MCP-PEG2K & not stable \\
\hline MCP-PEG5K & low (sedimentation after 6 h) \\
\hline MCP-PEG10K & stable \\
\hline MCP-PEG10K2 & stable \\
\hline MCP-PEG20K & low (sedimentation after 2 h and detection of aggregates) \\
\hline
\end{tabular}

For MCP-PEG2K, we failed to achieve stable dispersions, which may be attributable to the relatively low stabilizing effect of the short PEG chain. In contrast, for MCP-PEG5K, we initially obtained stable dispersions, but then observed sedimentation within a period of about $6 \mathrm{~h}$. Similar results were obtained after conversion of the MCPs with mPEGamine20K. The dispersions were not stable, and sedimentation occurred after about $2 \mathrm{~h}$. The reasons for the sedimentation of MCP-PEG5K and MCP-PEG20K are probably due to aggregation occurring during synthesis, because mPEG-amine5K does not stabilize sufficiently and mPEG-amine20K probably reacts too slowly due to the chain lengths. The only promising results were achieved using mPEG-amine10K, which led to stable MCP-PEG10K dispersions with a trend to form a concentration gradient after several days but without any changes in hydrodynamic diameter measured by DLS. Therefore, we decided to exclusively use MCP-PEG10K for further work. To investigate the possibility of physisorption of MPEG-amine10K to the MCP surface, instead of amide formation, the same reaction conditions were applied in control experiments, but sulfo-NHS and EDC 
were omitted in one case and EDC in the other. The results of the first experiment were unchanged MCPs and in the second the pronounced formation of aggregates was observed. The next step in this study was to convert MCP-PEG10K with mPEG-amine10K a second time to further optimize the MPI tracers blood half-life by increasing PEG density on the MCPs surfaces. The resulting MCP-PEG10K2 dispersions were stable without a tendency for gradient formation. DLS measurements in general showed a significant increase in hydrodynamic diameters of the MPEG-amine-converted MCPs compared with the parent MCPs. MCP-PEG20K displayed a very strong increase in hydrodynamic diameters and different from all other pegylated MNPs, a high proportion of aggregates could be detected. (For DLS results of MCP-PEG5K and MCP-PEG20K, please see supplement Figures S2 and S3.) The results of the DLS measurements of MCPs, MCP-PEG10K and MCP-PEG10K2 by volume are shown in Figure 2. Hydrodynamic diameters increased with each conversion, probably indicating higher PEG surface density in each case.

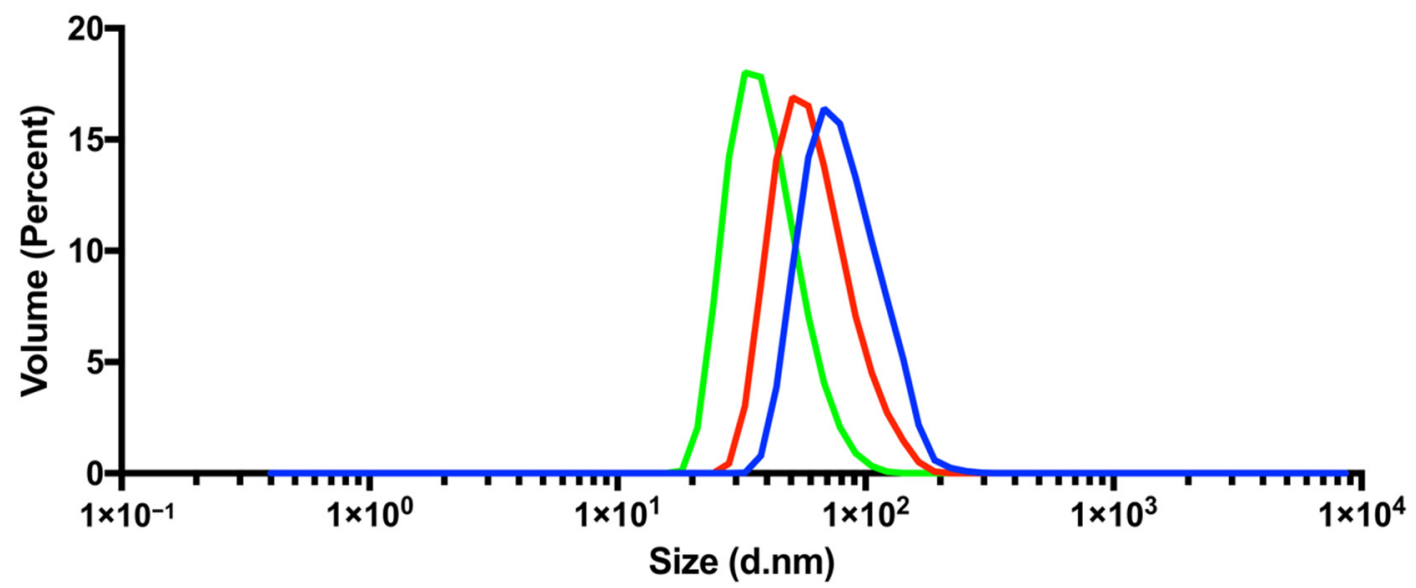

Figure 2. DLS results for MCPs (green), MCP-PEG10K (red) and MCP-PEG10K2 (blue). Graphs represent mean of 6 volume measurements. (For size distribution by intensity and DLS results of MCP, MCP-PEG5K, MCP-PEG10K, MCP-PEG10K2 and MCP-PEG20K please see supplement Figures S1-S3).

Z-Average values also increased with every conversion, and $\zeta$-potentials decreased from MCP to the pegylated MCP because of the reduced surface charge after the reaction with $\mathrm{mPEG}$-amine10K (Table 2). A further decrease in Zeta potential value would also be expected after the second pegylation, but with such small values close to zero, large deviations can occur due to the large $\mathrm{pH}$ value sensitivity.

Table 2. Properties of the pegylated MCPs and the parent MCP. (For corresponding data of MCP-PEG5K please see supplement Table S1).

\begin{tabular}{|c|c|c|c|c|c|c|}
\hline Tracer & $\begin{array}{c}\mathrm{r} 1 \\
\mathrm{~L} \mathrm{mmol}^{-1} \mathrm{~s}^{-1}\end{array}$ & $\mathrm{~L} \mathrm{mmol}^{-1} \mathrm{~s}^{-1}$ & $\begin{array}{c}\mathrm{d}_{\mathrm{V}} \mathrm{DLS} \\
\mathrm{nm}\end{array}$ & Z-Average nm & PdI & $\begin{array}{c}\zeta \text {-Potential } \\
{[\mathrm{mV}]}\end{array}$ \\
\hline $\mathrm{MCP}$ & 21 & 346 & 40.8 & 49.4 & 0.114 & -38.9 \\
\hline MCP-PEG10K & 19 & 404 & 64.0 & 78.5 & 0.126 & -3.2 \\
\hline MCP-PEG10K2 & 22 & 427 & 84.1 & 103.0 & 0.128 & -3.4 \\
\hline
\end{tabular}

Given in Table 2 are relaxivities $\mathrm{r} 1$ and $\mathrm{r} 2$, measured by TD- ${ }^{1} \mathrm{H}$ NMR. Also shown are the mean hydrodynamic diameter by volume $(\mathrm{dv})$, the intensity-weighted mean hydrodynamic size (Z-Average), the polydispersity index (PDI) and the zeta potential ( $\zeta$ ), all measured by DLS. Conversion of the activated MNP surface with the MPEG-amines could be examined by FTIR measurement for MCP-PEG10K and MCP-PEG10K2 (Figure 3). The mPEG-amine-specific bands are clearly detectable in MCP-PEG10K and even more markedly in MCP-PEG10K2, which might indicate a higher PEG density on the MNP surfaces after the second conversion. Furthermore, there are two bands at $1565 \mathrm{~cm}^{-1}$ and 
$1649 \mathrm{~cm}^{-1}$ in the FTIR spectrum of MCP-PEGK2 (Figure 3d), which can be attributed to amide bonds, which are formed during the pegylation reaction [40,41]. Please note that these bands (Amine I and II) are not very pronounced, because there is only one amino group per PEG chain with a molecular mass of $10 \mathrm{kD}$. In Figure $3 \mathrm{c}$, these bands are not visible, possible due to water content of the sample. This is another strong indication for a successful linkage of the mPEG-Amine10K to the MCPs surfaces.

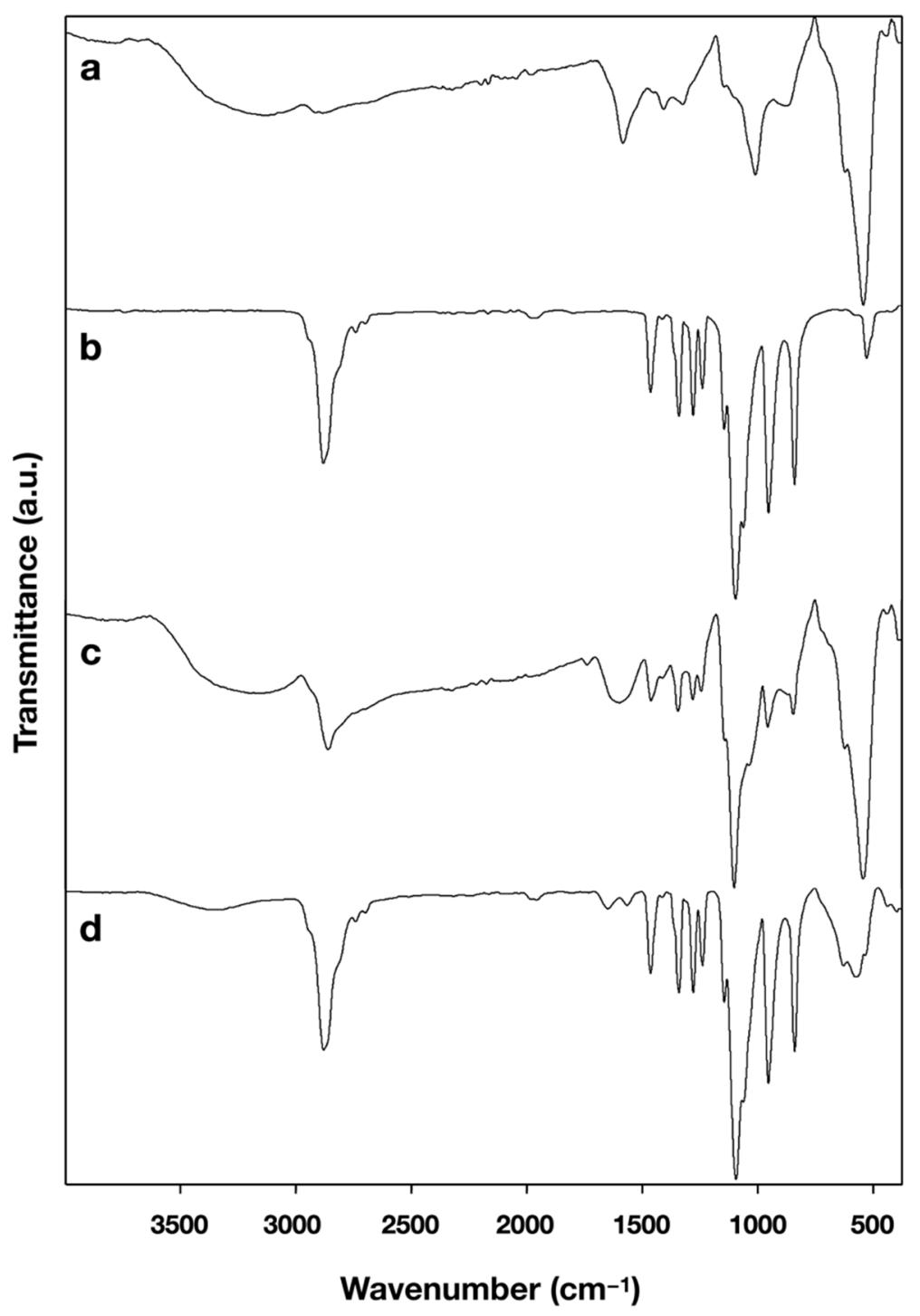

Figure 3. (a-d). FTIR spectra of (a) MCP, (b) mPEG-amine10K, (c) MCP-PEG10K and (d) MCPPEG10K2. For a list of the characteristic FTIR absorption bands and their assignment please see supplement Tables S4-S7.

Transmission electron microscopy (TEM) analysis of MCP and the two pegylated variants, MCP-PEG10K and MCP-PEG10K2, show the typical multicore structure of MCP (Figure 4), which is also preserved in the pegylated MCP [25]. It seems that there are only small differences between the parent MCPs and the pegylated MCPs in TEM, such as a possibly smaller degree of aggregation during grid preparation, and the difference is likely to be greater for the doubly pegylated variant. Note though that the difference might also be attributable to the selection of different areas for TEM. Therefore, further, more detailed investigations like x-ray diffraction (XRD), Mössbauer and small and wide-angle X-ray scattering (SAXS, WAXS) are needed, to determine the exact crystallographic phase and core structure of MCP. In particular, the latter is still unknown but seems to be fundamentally 
different from that of single core particles [25]. The selected area electron diffraction (SAED) pattern of MCPs (Figure $4 \mathrm{~d}$ ) indicates that the MNPs consist of magnetite/maghemite.
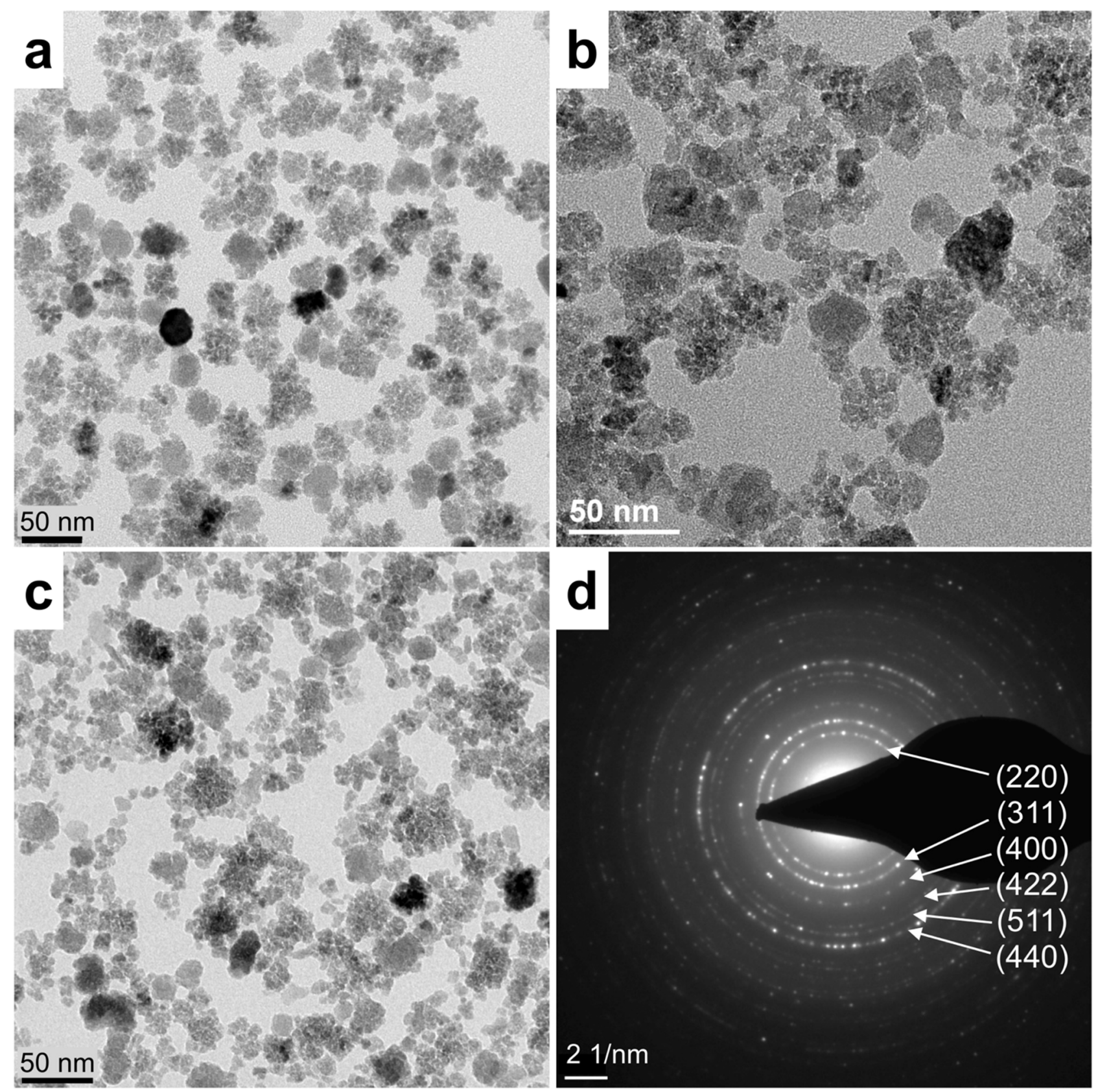

Figure 4. (a-d). TEM images of (a) MCP, (b) MCP-PEG10K and (c) MCP-PEG10K2, and (d) corresponding SAED pattern of MCP. Scale bar for SAED pattern is $2 \mathrm{~nm}^{-1}$. (For TEM image of MCP-PEG5K, please see supplement Figure S4).

The MNPs were also measured by MPS, which can be regarded as a zero-dimensional MPI scanner without spatial resolution [42]. The amplitudes of the harmonics, normalized to the iron amount in the sample, of the pegylated and doubly pegylated MCPs at $12 \mathrm{mT}$ and $25 \mathrm{kHz}$ were almost identical, indicating that pegylation has no significant influence on the dynamic magnetic properties of the core structure (Figure 5). Conversely, for MCPPEG5K, the amplitudes of the harmonics were significantly reduced (for MPS data of MCP-PEG5K, please see supplement Figure S5). This might have been caused by partial MNP aggregation during the synthesis process or by the presumably insufficient stabilizing effect of the $5 \mathrm{kD}$ peg chains. The large magnetic core diameters of MCPs need effective 
stabilization to prevent aggregation [25]. Once aggregated, the relatively large magnetic moments of the MCPs interact within an aggregate via a dipole-dipole interaction, that often slows down the dynamics of the moments [43]. If the subsequently increased lag of the moment behind the excitation field is large enough, the MPS amplitude decreases.

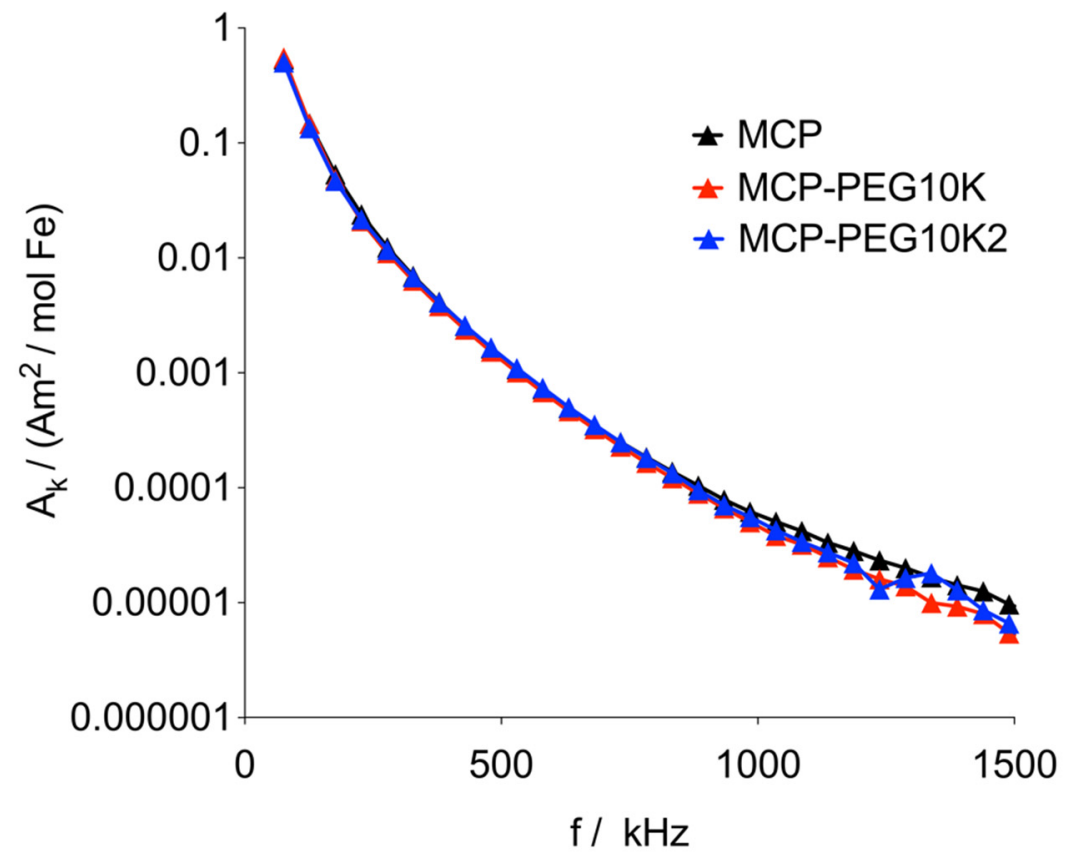

Figure 5. MPS results for MCP, MCP-PEG10K and MCP-PEG10K2 at $12 \mathrm{mT}$ and $25 \mathrm{kHz}$. Data are plotted as magnetic moment (normalized to iron content) versus frequency. Only odd harmonics are shown, and lines have been added to guide the eye.

The saturation magnetization $\left(M_{\mathrm{S}}\right)$ of MCP-PEG10K and MCP-PEG10K2 is also as high as that of $\mathrm{MCP}$, within the range of the uncertainty of $4 \%$ (sample adjustment + concentration). We assume that the atomic structure of the magnetic phase did not change during the pegylation steps. If this assumption is true, the $M(\mathrm{H})$ curves of the different samples have to match within the field range of saturation. While $M_{\mathrm{s}}$ of MCP and MCPPEG10K (Note: full saturation is not achieved at $\mathrm{H}=790 \mathrm{kA} / \mathrm{m}$ ) is $5.87 \mathrm{Am}^{2} / \mathrm{mol}(\mathrm{Fe}$ ) and $5.75 \mathrm{Am}^{2} / \mathrm{mol}(\mathrm{Fe})$, respectively, that of MCP-PEG10K2 is $6.18 \mathrm{Am}^{2} / \mathrm{mol}(\mathrm{Fe})$. The last value could be slightly overestimated. This was concluded from the good agreement of the MPS curves (Figure 5). Thus, this difference is due to a to a slight deviation of the sample from the center position in the $\mathrm{M}(\mathrm{H})$ measurement rather than an underestimation of iron content. Accordingly, we multiplied the $\mathrm{M}(\mathrm{H})$ curve of MCP-PEG10K2 by 0.93 , yielding a match of the $\mathrm{M}(\mathrm{H})$ data at high fields. This way, differences between the $\mathrm{M}(\mathrm{H})$ curves in the lower and middle field range of the curve become apparent. Here, the curves differ only slightly in shape (Figure 6). From this, we conclude that neither the magnetic cores of the MCPs nor their size distribution changed significantly after pegylation. The observed slight alterations indicate very small changes in core size distribution, probably introduced by the additional washing steps. 


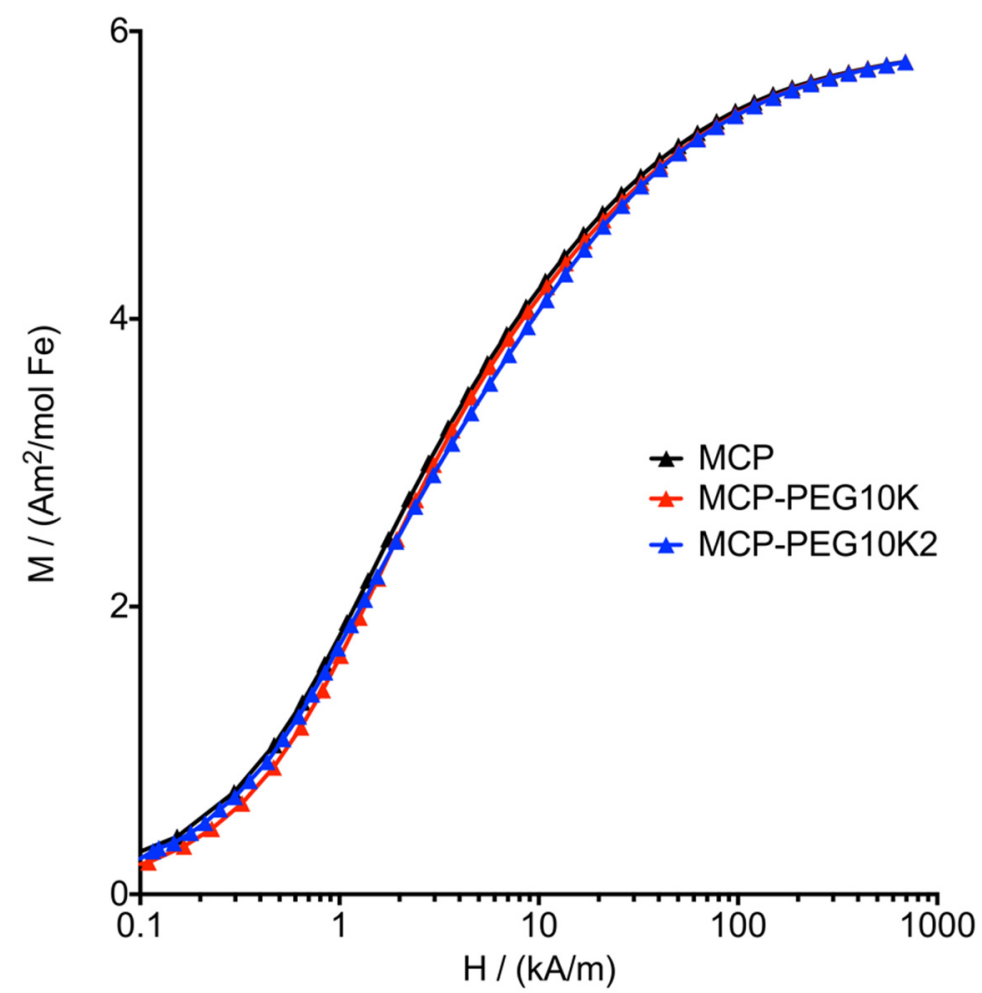

Figure 6. Molar magnetization $M$ as a function of applied external field $H$ measured for MCP, MCP-PEG10K and MCP-PEG10K2 at $295 \mathrm{~K}$. For a better comparison of the curve shapes, the data of MCP-PEG10K2 were multiplied by 0.93.

\subsection{Animal Blood Half-Life Determination Using MRI}

\subsubsection{Blood Half-Life Determination of MCP-PEG10K}

For a first evaluation of the blood half-life of MCP-PEG10K, MNPs were administered into the tail vein of two rats at doses of 50 and $100 \mu \mathrm{mol} \mathrm{Fe} / \mathrm{kg}$. The rats were then examined in a 1.5 Tesla MRI scanner to measure transient intravascular signal enhancement over time. The blood half-life of MCP-PEG10K was 1.8 and $5.2 \mathrm{~min}$ at 50 and $100 \mu \mathrm{mol} \mathrm{Fe} / \mathrm{kg}$, respectively (Figure 7). The half-life was significantly reduced compared to similar MCPs without pegylation, for which 8.8 and $17.4 \mathrm{~min}$ at 50 and $100 \mu \mathrm{mol} \mathrm{Fe} / \mathrm{kg}$ have been reported [25]. Based on these results, we synthesized MCP-PEG10K2 by a second reaction of MCP-PEG10K with mPEG-amine10K to further increase the PEG density on the MCPs surfaces.

\subsubsection{Blood Half-Life Determination of MCP-PEG10K2}

For determination of the blood half-life of MCP-PEG10K2, MNP were administered to a total of three healthy 12-week-old male Sprague Dawley rats and measured in the then newly installed 3 Tesla MRI scanner using a T1-weighted pulse sequence after administration of a dose of $50 \mu \mathrm{mol} \mathrm{Fe} / \mathrm{kg}$ (Figure 8). 


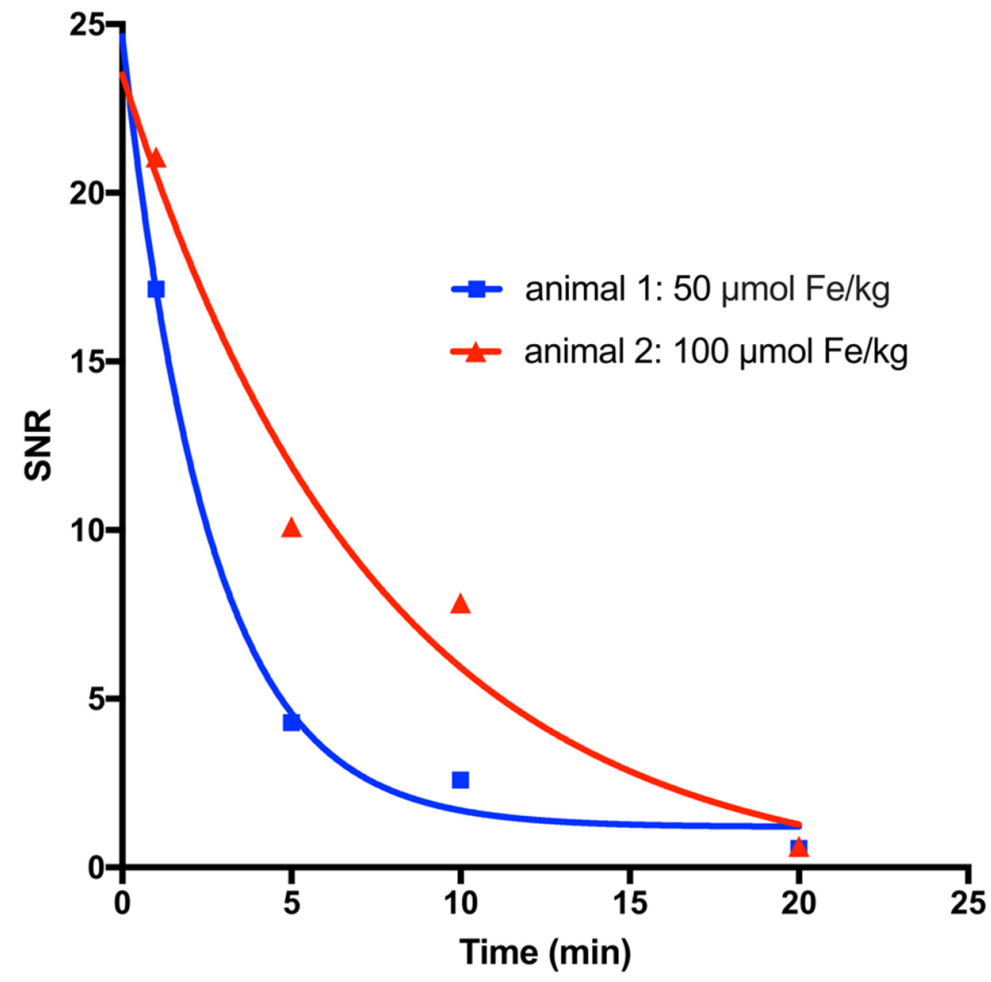

Figure 7. T1-weighted half-life of MCP-PEG10K measured using MRI in rats administered doses of 50 and $100 \mu \mathrm{mol} \mathrm{Fe} / \mathrm{kg}$. Scheme 1. 8 and $5.2 \mathrm{~min}$, respectively.
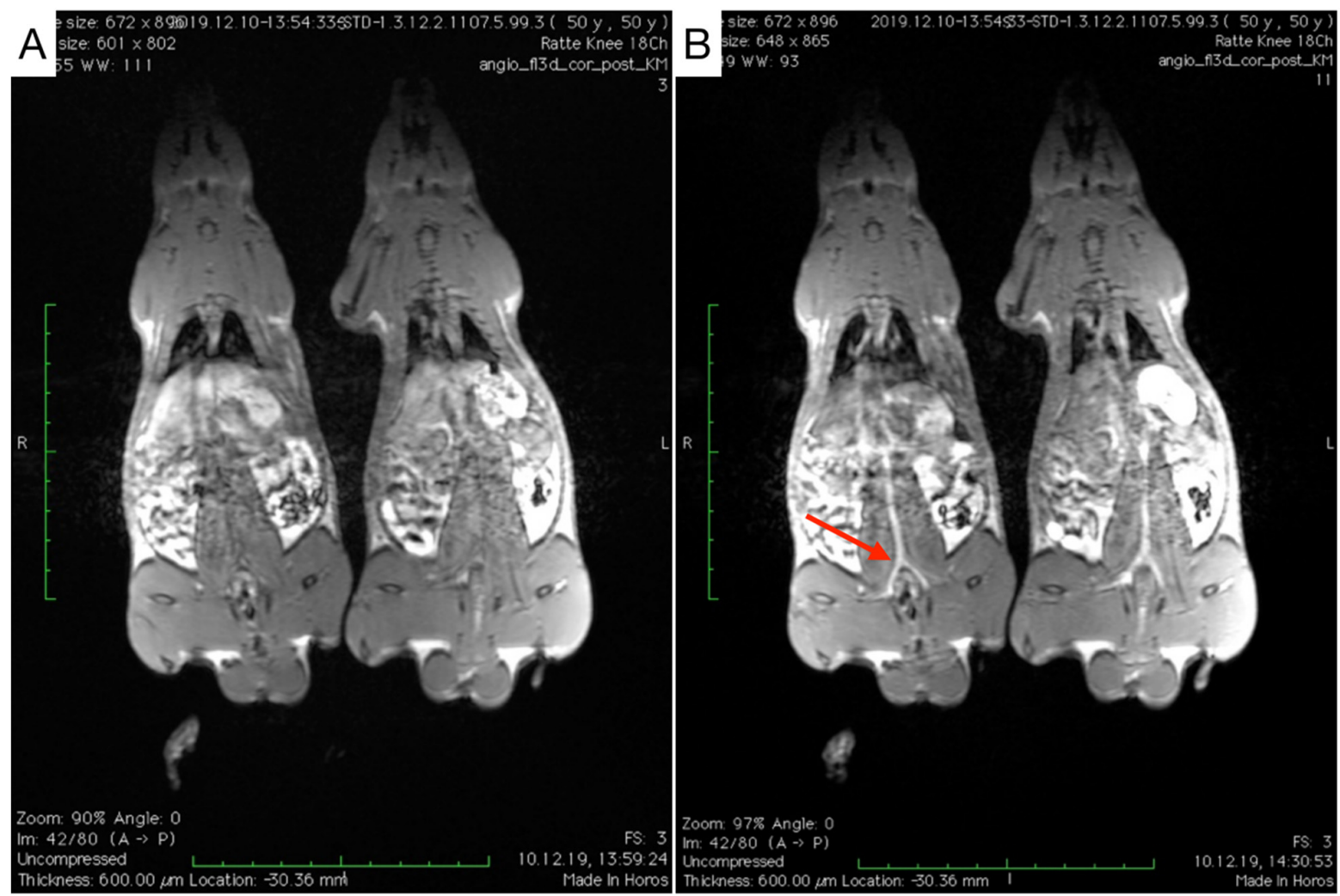

Figure 8. T1-weighted MR images of 2 male Sprague Dawley rats before (A) and 20 min after administration (B) of MCPPEG10K2 $(50 \mu \mathrm{mol} \mathrm{Fe} / \mathrm{kg})$. The red arrow in B indicates the area where signal enhancement was measured to determine the blood half-life of MCP-PEG10K2. 
The blood half-life of MCP-PEG10K2 determined by T1w MRI in three measurements was $45.4,54.1$ and $86.8 \mathrm{~min}$, from which a mean blood half-life of $62.1 \mathrm{~min}$ was calculated (Figure 9).

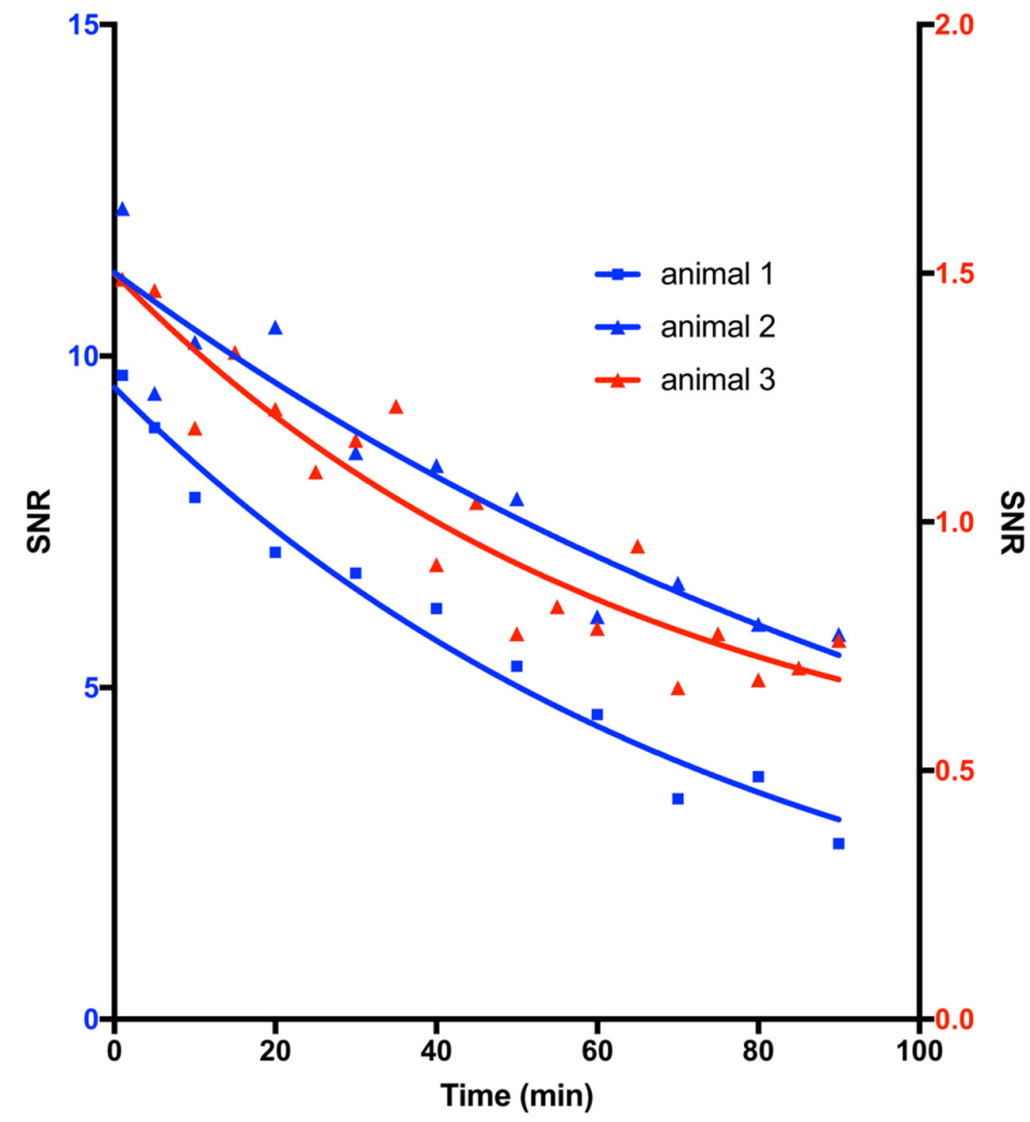

Figure 9. T1-weighted half-life of MCP-PEG10K2 measured using MRI in rats following administration of a dose of $50 \mu \mathrm{mol} \mathrm{Fe} / \mathrm{kg}$. Shown is the course of MRI signal intensity over time. The blood half-lives calculated from the measured data were $54.1 \mathrm{~min}$ for animal 1, $86.8 \mathrm{~min}$ for animal 2 and $45.4 \mathrm{~min}$ for animal 3.

To explain the totally different in vivo behavior of MCP-PEG10K and MCP-PEG10K2 one should take a closer look at what happens in vivo with MNPs in general. After intravenous injection of a tracer, serum/complement proteins are rapidly adsorbed on the surface of the MNPs [44,45]. This process is known as opsonization and the adsorbed proteins are called opsonins [46] and is driven by the tendency of the body fluid/MNP system to minimize free enthalpy, also known as Gibbs energy [45]. Consequently, in general, the rapidly formed protein shell, or protein corona, gives the MNPs their in vivo biological identity and fundamentally changes the initial surface properties, thus determining the subsequent in vivo behavior of the MNPs $[44,47]$. On the other hand, the initial surface properties such as surface charge and lipophilicity/hydrophilicity determine which kinds of proteins are absorbed. It is assumed that opsonins on an MNP surface mostly boost their recognition by the reticuloendothelial system (RES) and thus enhance phagocytosis [31]. This can be advantageous if, for example, MNPs are administered to track macrophages, while, for other applications such as selective targeting or cardiovascular imaging, a sufficiently long blood half-life is urgently required. One common method to extend blood half-life is to cover the MNPs surfaces with PEG, which strongly reduces the interaction of the MNPs surfaces with opsonins [31]. Many reports in the literature describe a higher effectiveness of protein shielding for high-molecular-weight PEG chains, although the resulting PEG density on the MNPs surfaces is significantly lower compared to low-molecular-weight PEG chains $[35,48]$. The "conformational cloud" generated by 
the large number of possible conformations of high-molecular-weight PEG chains and fast transition have been reported to reduce the surface charge and protein interactions [29]. The effectiveness of this stealth effect is not only dependent on the molecular weight of the PEG polymer but is also strongly influenced by its surface density. It has been shown for pegylated gold nanoparticles that there is an optimum of PEG surface density, above which protein resistance decreases [49]. The conversion of MCPs with mPEG-amine10K leads to stable dispersions of MCP-PEG10K with a surface charge near zero. Nevertheless, the MRI blood half-life of MCP-PEG10K was shorter in rats compared with unpegylated MCPs, which means that uptake by the RES was increased after the first conversion with PEG and not reduced. This may have been caused by a relatively low PEG density on the MNPs surfaces and a resulting "mushroom" or "brush" configuration of the PEGs bound to the surface. Such a configuration is not dense enough to ensure sufficient shielding of the MNPs surfaces [50]. This could lead to the accumulation of proteins on the particle surface, which promote increased uptake by the RES. The longer blood half-life of MCP-PEG10K2 measured in rats after the second conversion with $\mathrm{mPEG}$-amine10K is probably attributable to a higher PEG density on the MNPs surfaces, which was also confirmed by our results of the physicochemical characterization.

\subsection{Determination of Organ Distribution of MCP-PEG10K2 by MPS}

MR images of the rats acquired after $24 \mathrm{~h}$ were assessed for visual qualitative determination of MNP organ distribution. The results indicate that MNPs are mainly taken up in the liver and spleen [51]. Afterwards, the rats were euthanized and the organs were removed, cut into small pieces, and the MNP content was quantified by MPS. The highest concentrations of MNPs were found in the spleen and liver and only very low concentrations in the kidneys, heart and lungs (Figure 10).

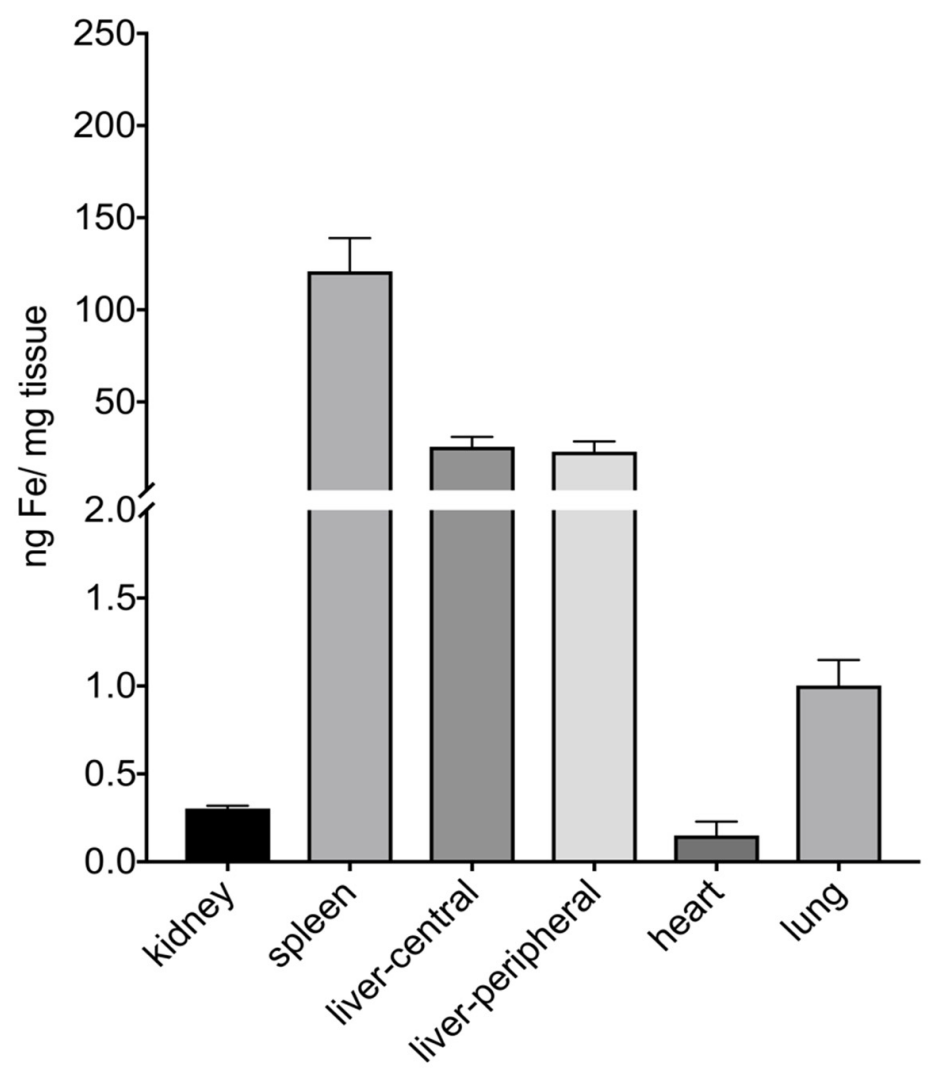

Figure 10. Postmortem organ distribution of MCP-PEG10K2 in three rats, $24 \mathrm{~h}$ after administration of $50 \mu \mathrm{mol} / \mathrm{kg}$ MCP-PEG10K2 determined by MPS $\left(25 \mathrm{mT}, 25 \mathrm{kHz}\right.$ and $\left.37{ }^{\circ} \mathrm{C}\right)$. The results of measurements in organs of treated and untreated animals (control) are summarized in supplement Tables S2 and S3. 
The organ distribution of MCPs quantified by MPS and the qualitative results obtained from T2*-weighted MR images of liver and spleen (for MR images, please see supplement Figure S7) are similar to those reported for pegylated MNPs synthesized by thermal decomposition [52].

\section{Conclusions and Outlook}

We successfully modified MCPs for use as a blood pool MPI tracer using a surface pegylation strategy. After a second conversion with $\mathrm{mPEG}$-amine10K, the resulting doubly pegylated MCP-PEG10K2 showed a significantly extended blood half-life measured by MRI in rats, indicating that an adequate PEG surface density was accomplished. In addition, our work is also a first proof of principle that surface modification can be achieved while at the same time preserving the excellent magnetic properties of our MCPs with a view to meeting the specific requirements of new MPI applications. In the future, the same technique can now be used to modify the particle surface of MCPs with amino-groupbearing molecules such as peptides, antibodies, proteins in general, drugs or functionalized PEG chains, to name just a few $[53,54]$. The significantly prolonged MRI blood half-life makes MCP-PEG10K2 a very promising blood pool MPI tracer. Therefore, the next step will be to test MCP-PEG10K2 in vivo for cardiovascular MPI imaging.

Supplementary Materials: The following files are available online at https:/ /www.mdpi.com/ article/10.3390/nano11061532/s1: Protocol S1: Synthesis of MCP-PEG2K; Protocol S2: Synthesis of MCP-PEG20K; Figure S1: DLS data (intensity) of MCP, MCP-PEG10K and MCP-PEG10K2; Figure S2: DLS data (volume) of MCP-PEG5K and MCP-PEG20K; Figure S3: DLS data of MCP-PEG5K and MCP-PEG20K (intensity); Figure S4: TEM image of MCP-PEG5K; Figure S5: MPS data of MCP and MCP-PEG5K at $12 \mathrm{mT}$ and $25 \mathrm{kHz}$; Figure S6: MPS data of MCP-PEG10K2 in aqueous dispersion and polyacrylamide (PAA) gel at $25 \mathrm{mT}$ and $25 \mathrm{kHz}$; Figure S7: Qualitative biodistribution of MCPPEG10K2 in representative T2 * w MR images before and after injection ( $24 \mathrm{~h})$ of $50 \mu \mathrm{mol} \mathrm{Fe} / \mathrm{kg}$; Table S1: Compilation of properties of MCP-PEG5K; Table S2: Post mortem MPS measurements in organs of 3 rats, $24 \mathrm{~h}$ after administration of $50 \mu \mathrm{mol} / \mathrm{kg}$ MCP-PEG10K2 (MPS parameters: $25 \mathrm{mT}$, $25 \mathrm{kHz}$ and $37^{\circ} \mathrm{C}$ ); Table S3: Post mortem MPS measurements in organs of 3 untreated control rats (MPS parameters: $25 \mathrm{mT}, 25 \mathrm{kHz}$ and $37^{\circ} \mathrm{C}$ ); Table S4: Characteristic FTIR absorption bands of MCP; Table S5: Characteristic FTIR absorption bands of mPEG-Amine10K; Table S6: Characteristic FTIR absorption bands of MCP-PEG10K; Table S7: Characteristic FTIR absorption bands of MCP-PEG10K2.

Author Contributions: Conceptualization, H.K.; methodology, H.K., A.M. and D.E.; software, A.M. and D.E.; validation, A.M., D.E., M.T. and F.W.; formal analysis, H.K., A.M. and D.E.; investigation, H.K., A.M., D.E. and O.K.; resources, N.S.; data curation, H.K.; writing-original draft preparation, H.K., A.M. and D.E.; writing—review and editing, A.M., D.E., O.K., M.T., F.W. and J.S.; visualization, H.K. and A.M.; supervision, J.S.; project administration, H.K.; funding acquisition, F.W., M.T., B.H. and J.S. All authors have read and agreed to the published version of the manuscript.

Funding: The research was funded by the German Research Foundation (DFG) research program: SFB 1340/1 2018: "Matrix in Vision: In vivo Visualization of Extracellular Matrix Pathology" (Collaborative Research Center). Project number: 372486779, projects A02 and C01. The project was further funded by the German Research Foundation (GRK2260, BIOQIC).

Data Availability Statement: The data presented in this study are available on request from the corresponding author.

Acknowledgments: We thank Bettina Herwig for language editing and Sören Selve for conducting the TEM studies at ZELMI (TU Berlin).

Conflicts of Interest: The authors declare no conflict of interest. 


\section{References}

1. Beik, J.; Abed, Z.; Ghoreishi, F.S.; Hosseini-Nami, S.; Mehrzadi, S.; Shakeri-Zadeh, A.; Kamrava, S.K. Nanotechnology in hyperthermia cancer therapy: From fundamental principles to advanced applications. J. Control. Release 2016, 235, $205-221$. [CrossRef]

2. Hedayatnasab, Z.; Abnisa, F.; Daud, W.M.A.W. Review on magnetic nanoparticles for magnetic nanofluid hyperthermia application. Mater. Des. 2017, 123, 174-196. [CrossRef]

3. Spinowitz, B.S.; Kausz, A.T.; Baptista, J.; Noble, S.D.; Sothinathan, R.; Bernardo, M.V.; Brenner, L.; Pereira, B.J.G. Ferumoxytol for treating iron deficiency anemia in CKD. J. Am. Soc. Nephrol. 2008, 19, 1599-1605. [CrossRef]

4. Wu, K.; Su, D.; Saha, R.; Wong, D.; Wang, J.-P. Magnetic particle spectroscopy-based bioassays: Methods, applications, advances, and future opportunities. J. Phys. D Appl. Phys. 2019, 52, 173001. [CrossRef]

5. Xianyu, Y.; Dong, Y.; Wang, Z.; Xu, Z.-L.; Huang, R.; Chen, Y. Broad-Range Magnetic Relaxation Switching Bioassays Using Click Chemistry-Mediated Assembly of Polystyrene Beads and Magnetic Nanoparticles. ACS Sens. 2019, 4, 1942-1949. [CrossRef]

6. Schnorr, J.; Wagner, S.; Abramjuk, C.; Drees, R.; Schink, T.; Schellenberger, E.A.; Pilgrimm, H.; Hamm, B.; Taupitz, M. Focal liver lesions: SPIO-, gadolinium-, and ferucarbotran-enhanced dynamic T1-weighted and delayed T2-weighted MR imaging in rabbits. Radiology 2006, 240, 90-100. [CrossRef]

7. Wagner, M.; Wagner, S.; Schnorr, J.; Schellenberger, E.; Kivelitz, D.; Krug, L.; Dewey, M.; Laule, M.; Hamm, B.; Taupitz, M. Coronary MR angiography using citrate-coated very small superparamagnetic iron oxide particles as blood-pool contrast agent: Initial experience in humans. J. Magn. Reson. Imaging 2011, 34, 816-823. [CrossRef]

8. Knopp, T.; Gdaniec, N.; Möddel, M. Magnetic particle imaging: From proof of principle to preclinical applications. Phys. Med. Biol. 2017, 62, R124-R178. [CrossRef]

9. Gleich, B.; Weizenecker, J. Tomographic imaging using the nonlinear response of magnetic particles. Nat. Cell Biol. 2005, 435, 1214-1217. [CrossRef]

10. Franke, J.; Heinen, U.; Lehr, H.; Weber, A.; Jaspard, F.; Ruhm, W.; Heidenreich, M.; Schulz, V. System Characterization of a Highly Integrated Preclinical Hybrid MPI-MRI Scanner. IEEE Trans. Med. Imaging 2016, 35, 1993-2004. [CrossRef]

11. Paysen, H.; Loewa, N.; Stach, A.; Wells, J.; Kosch, O.; Twamley, S.; Makowski, M.R.; Schaeffter, T.; Ludwig, A.; Wiekhorst, F. Cellular uptake of magnetic nanoparticles imaged and quantified by magnetic particle imaging. Sci. Rep. 2020, 10, 1-8. [CrossRef]

12. Bulte, J.W. Superparamagnetic iron oxides as MPI tracers: A primer and review of early applications. Adv. Drug Deliv. Rev. 2019, 138, 293-301. [CrossRef]

13. Rauwerdink, A.M.; Weaver, J.B. Measurement of molecular binding using the Brownian motion of magnetic nanoparticle probes. Appl. Phys. Lett. 2010, 96, 33702. [CrossRef]

14. Bulte, J.W.M.; Walczak, P.; Gleich, B.; Weizenecker, J.; Markov, D.E.; Aerts, H.C.J.; Boeve, H.; Borgert, J.; Kuhn, M. MPI Cell Tracking: What Can We Learn from MRI? Proc. SPIE Int. Soc. Opt. Eng. 2011, 7965, 79650z. [CrossRef]

15. Li, L.; Jiang, W.; Luo, K.; Song, H.; Lan, F.; Wu, Y.; Gu, Z. Superparamagnetic iron oxide nanoparticles as MRI contrast agents for non-invasive stem cell labeling and tracking. Theranostics 2013, 3, 595-615. [CrossRef]

16. Du, Y.; Lai, P.T.; Leung, C.H.; Pong, P.W.T. Design of superparamagnetic nanoparticles for magnetic particle imaging (MPI). Int. J. Mol. Sci. 2013, 14, 18682-18710. [CrossRef] [PubMed]

17. Zhou, X.Y.; Tay, Z.W.; Chandrasekharan, P.; Yu, E.Y.; Hensley, D.W.; Orendorff, R.; Jeffris, K.E.; Mai, D.; Zheng, B.; Goodwill, P.W.; et al. Magnetic particle imaging for radiation-free, sensitive and high-contrast vascular imaging and cell tracking. Curr. Opin. Chem. Biol. 2018, 45, 131-138. [CrossRef]

18. Weller, D.; Salamon, J.M.; Frölich, A.; Möddel, M.; Knopp, T.; Werner, R. Combining Direct 3D Volume Rendering and Magnetic Particle Imaging to Advance Radiation-Free Real-Time 3D Guidance of Vascular Interventions. Cardiovasc. Interv. Radiol. 2020, 43, 322-330. [CrossRef]

19. Weizenecker, J.; Gleich, B.; Rahmer, J.; Dahnke, H.; Borgert, J. Three-dimensional real-timein vivomagnetic particle imaging. Phys. Med. Biol. 2009, 54, L1-L10. [CrossRef]

20. Talebloo, N.; Gudi, M.; Robertson, N.; Wang, P. Magnetic Particle Imaging: Current Applications in Biomedical Research. J. Magn. Reson. Imaging 2020, 51, 1659-1668. [CrossRef]

21. Ludewig, P.; Gdaniec, N.; Sedlacik, J.; Forkert, N.D.; Szwargulski, P.; Graeser, M.; Adam, G.; Kaul, M.G.; Krishnan, K.M.; Ferguson, R.M.; et al. Magnetic Particle Imaging for Real-Time Perfusion Imaging in Acute Stroke. ACS Nano 2017, 11, 10480-10488. [CrossRef]

22. Zhou, X.Y.; Jeffris, K.E.; Yu, E.Y.; Zheng, B.; Goodwill, P.W.; Nahid, P.; Conolly, S.M. Firstin vivomagnetic particle imaging of lung perfusion in rats. Phys. Med. Biol. 2017, 62, 3510-3522. [CrossRef]

23. Ferguson, R.M.; Khandhar, A.P.; Arami, H.; Hua, L.; Hovorka, O.; Krishnan, K.M. Tailoring the magnetic and pharmacokinetic properties of iron oxide magnetic particle imaging tracers. Biomed. Tech. Eng. 2013, 58, 493-507. [CrossRef]

24. Ferguson, R.M.; Khandhar, A.P.; Kemp, S.J.; Arami, H.; Saritas, E.U.; Croft, L.R.; Konkle, J.; Goodwill, P.W.; Halkola, A.; Rahmer, J.; et al. Magnetic particle imaging with tailored iron oxide nanoparticle tracers. IEEE Trans. Med Imaging 2015, 34, 1077-1084. [CrossRef]

25. Kratz, H.; Taupitz, M.; De Schellenberger, A.A.; Kosch, O.; Eberbeck, D.; Wagner, S.; Trahms, L.; Hamm, B.; Schnorr, J. Novel magnetic multicore nanoparticles designed for MPI and other biomedical applications: From synthesis to first in vivo studies. PLoS ONE 2018, 13, e0190214. [CrossRef] 
26. Kratz, H.; Mohtashamdolatshahi, A.; Eberbeck, D.; Kosch, O.; Hauptmann, R.; Wiekhorst, F.; Taupitz, M.; Hamm, B.; Schnorr, J. MPI Phantom Study with A High-Performing Multicore Tracer Made by Coprecipitation. Nanomaterials 2019, 9, 1466. [CrossRef]

27. Mohtashamdolatshahi, A.; Kratz, H.; Kosch, O.; Hauptmann, R.; Stolzenburg, N.; Wiekhorst, F.; Sack, I.; Hamm, B.; Taupitz, M.; Schnorr, J. In vivo magnetic particle imaging: Angiography of inferior vena cava and aorta in rats using newly developed multicore particles. Sci. Rep. 2020, 10, 1-9. [CrossRef]

28. Löwa, N.; Meier, F.; Welz, R.; Kratz, H.; Paysen, H.; Schnorr, J.; Taupitz, M.; Klein, T.; Wiekhorst, F. Novel platform for the multidimensional analysis of magnetic nanoparticles. J. Magn. Magn. Mater. 2021, 518, 167443. [CrossRef]

29. Knop, K.; Hoogenboom, R.; Fischer, D.; Schubert, U.S. Poly(ethylene glycol) in drug delivery: Pros and cons as well as potential alternatives. Angew. Chem. Int. Ed. 2010, 49, 6288-6308. [CrossRef]

30. de Schellenberger, A.A.; Kratz, H.; Farr, T.D.; Loewa, N.; Hauptmann, R.; Wagner, S.; Taupitz, M.; Schnorr, J.; Schellenberger, E. Labeling of mesenchymal stem cells for MRI with single-cell sensitivity. Int. J. Nanomed. 2016, 11, 1517-1535. [CrossRef]

31. Jokerst, J.V.; Lobovkina, T.; Zare, R.N.; Gambhir, S.S. Nanoparticle PEGylation for imaging and therapy. Nanomedicine 2011, 6, 715-728. [CrossRef]

32. Karakoti, A.; Das, S.; Thevuthasan, S.; Seal, S. PEGylated Inorganic Nanoparticles. Angew. Chem. Int. Ed. 2011, 50, 1980-1994. [CrossRef]

33. Gupta, V.; Bhavanasi, S.; Quadir, M.; Singh, K.; Ghosh, G.; Vasamreddy, K.; Ghosh, A.; Siahaan, T.J.; Banerjee, S.; Banerjee, S.K. Protein PEGylation for cancer therapy: Bench to bedside. J. Cell Commun. Signal. 2019, 13, 319-330. [CrossRef] [PubMed]

34. Hussain, Z.; Khan, S.; Imran, M.; Sohail, M.; Shah, S.W.A.; De Matas, M. PEGylation: A promising strategy to overcome challenges to cancer-targeted nanomedicines: A review of challenges to clinical transition and promising resolution. Drug Deliv. Transl. Res. 2019, 9, 721-734. [CrossRef] [PubMed]

35. Khandhar, A.P.; Keselman, P.; Kemp, S.J.; Ferguson, R.M.; Goodwill, P.W.; Conolly, S.M.; Krishnan, K.M. Evaluation of PEG-coated iron oxide nanoparticles as blood pool tracers for preclinical magnetic particle imaging. Nanoscale 2017, 9, 1299-1306. [CrossRef] [PubMed]

36. Scharlach, C.; Müller, L.; Wagner, S.; Kobayashi, Y.; Kratz, H.; Ebert, M.; Jakubowski, N.; Schellenberger, E. LA-ICP-MS Allows Quantitative Microscopy of Europium-Doped Iron Oxide Nanoparticles and is a Possible Alternative to Ambiguous Prussian Blue Iron Staining. J. Biomed. Nanotechnol. 2016, 12, 1001-1010. [CrossRef] [PubMed]

37. Kawasaki, H.; Takeda, Y.; Arakawa, R. Mass spectrometric analysis for high molecular weight synthetic polymers using ultrasonic degradation and the mechanism of degradation. Anal. Chem. 2007, 79, 4182-4187. [CrossRef]

38. Koda, S.; Taguchi, K.; Futamura, K. Effects of frequency and a radical scavenger on ultrasonic degradation of water-soluble polymers. Ultrason. Sonochem. 2011, 18, 276-281. [CrossRef]

39. Zou, Q.; Pu, Y.; Han, Z.; Fu, N.; Li, S.; Liu, M.; Huang, L.; Lu, A.; Mo, J.; Chen, S. Ultrasonic degradation of aqueous dextran: Effect of initial molecular weight and concentration. Carbohydr. Polym. 2012, 90, 447-451. [CrossRef]

40. Kong, J.; Yu, S. Fourier Transform infrared spectroscopic analysis of protein secondary structures. Acta Biochim. Biophys. Sin. 2007, 39, 549-559. [CrossRef]

41. Ji, Y.; Yang, X.; Ji, Z.; Zhu, L.; Ma, N.; Chen, D.; Jia, X.; Tang, J.; Cao, Y. DFT-Calculated IR Spectrum Amide I, II, and III Band Contributions of N-Methylacetamide Fine Components. ACS Omega 2020, 5, 8572-8578. [CrossRef] [PubMed]

42. Biederer, S.; Knopp, T.; Sattel, T.F.; Lüdtke-Buzug, K.; Gleich, B.; Weizenecker, J.; Borgert, J.; Buzug, T. Magnetization response spectroscopy of superparamagnetic nanoparticles for magnetic particle imaging. J. Phys. D Appl. Phys. 2009, 42, 205007. [CrossRef]

43. Eberbeck, D.; Trahms, L. Experimental investigation of dipolar interaction in suspensions of magnetic nanoparticles. J. Magn. Magn. Mater. 2011, 323, 1228-1232. [CrossRef]

44. Tenzer, S.; Docter, D.; Kuharev, J.; Musyanovych, A.; Fetz, V.; Hecht, R.; Schlenk, F.; Fischer, D.; Kiouptsi, K.; Reinhardt, C.; et al. Rapid formation of plasma protein corona critically affects nanoparticle pathophysiology. Nat. Nanotechnol. 2013, 8, 772-781. [CrossRef]

45. Ke, P.C.; Lin, S.; Parak, W.J.; Davis, T.P.; Caruso, F. A Decade of the Protein Corona. ACS Nano 2017, 11, 11773-11776. [CrossRef]

46. Podila, R.; Chen, R.; Ke, P.C.; Brown, J.M.; Rao, A.M. Effects of surface functional groups on the formation of nanoparticle-protein corona. Appl. Phys. Lett. 2012, 101, 263701. [CrossRef]

47. Caracciolo, G.; Farokhzad, O.C.; Mahmoudi, M. Biological Identity of Nanoparticles In Vivo: Clinical Implications of the Protein Corona. Trends Biotechnol. 2017, 35, 257-264. [CrossRef]

48. Gombotz, W.R.; Guanghui, W.; Horbett, T.A.; Hoffman, A.S. Protein adsorption to poly(ethylene oxide) surfaces. J. Biomed. Mater. Res. 1991, 25, 1547-1562. [CrossRef]

49. Unsworth, L.D.; Sheardown, H.; Brash, J.L. Protein Resistance of Surfaces Prepared by Sorption of End-Thiolated Poly(ethylene glycol) to Gold: Effect of Surface Chain Density. Langmuir 2005, 21, 1036-1041. [CrossRef]

50. Yang, Q.; Jones, S.W.; Parker, C.L.; Zamboni, W.C.; Bear, J.E.; Lai, S.K. Evading immune cell uptake and clearance requires PEG grafting at densities substantially exceeding the minimum for brush conformation. Mol. Pharm. 2014, 11, 1250-1258. [CrossRef]

51. Arami, H.; Khandhar, A.P.; Liggitt, D.; Krishnan, K.M. In vivo delivery, pharmacokinetics, biodistribution and toxicity of iron oxide nanoparticles. Chem. Soc. Rev. 2015, 44, 8576-8607. [CrossRef]

52. Khandhar, A.P.; Ferguson, R.M.; Arami, H.; Krishnan, K.M. Monodisperse magnetite nanoparticle tracers for in vivo magnetic particle imaging. Biomaterials 2013, 34, 3837-3845. [CrossRef] 
53. Sapsford, K.E.; Algar, W.R.; Berti, L.; Gemmill, K.B.; Casey, B.J.; Oh, E.; Stewart, M.H.; Medintz, I.L. Functionalizing nanoparticles with biological molecules: Developing chemistries that facilitate nanotechnology. Chem. Rev. 2013, 113, 1904-2074. [CrossRef] [PubMed]

54. Wang, Y.; Jia, H.-Z.; Han, K.; Zhuo, R.-X.; Zhang, X.-Z. Theranostic magnetic nanoparticles for efficient capture and in situ chemotherapy of circulating tumor cells. J. Mater. Chem. B 2013, 1, 3344-3352. [CrossRef] [PubMed] 